\title{
ANALISIS CSR DAN HUBUNGANYA DENGAN PROPITABILITAS MASA COVID-19 PADA PERUSAHAAN KONSUMSI
}

\author{
Rafika \\ Fakultas Ekonomi, Universitas IGM Palembang \\ Email: rafikasari@uigmac.id \\ Yunita Maharani \\ STIE IBEK, Pangkalpinang \\ Email: yunitamaharani@gmail.com
}

\begin{abstract}
Corporate Social Responsibility (CSR) is a principle of humanity or a company's concern for its stakeholders or its social environment where company ethics is judged by the way a company treats its stakeholders. This study will analyze corporate social responsibility and its disclosure and its effect on propitability, data analysis methods using simple regression. The results of the study state that corporate social responsibility has a significant positive effect on financial performance or profitability in consumer goods manufacturing companies listed on the Indonesian Stock Exchange in 2019, this is in line with the steakholder theory which suggests companies not only be able to improve their performance if the company can care about all its steakholders, including social environment. This research contributes to the company in order to improve the ethics of social care and make disclosure of its social activities in order to improve company performance.)
\end{abstract}

Keywords: CSR, Profitabilitalty, Covid-19

\begin{abstract}
Abstrak
Corporate Social Responsibility (CSR) merupakan suatu prinsip kemanusian atau kepedulian perusahaan terhadap steakholdernya atau lingkungan sosialnya dimana etika perusahaan dinilai dari cara perusahaan memperlakukan steakholdernya, Penelitian ini akan menganalisis tentang Corporate social responsibility dan pengungkapanya serta pengaruhnya terhadap propitabilitas , metode analisis data dengan megunakan regresi sederhanana hasil penelitian menyatakan bahwa Corporate social responsibility berpengaruh secara positif signifikan terhadap kinerja keuangan atau profitabilitas pada perusahaan manufaktur sektro barang konsumsi yang terdaftar dibursa efek dindonesia tahun 2019hal ini sejalan dengan teori steakholder yang menyarakan perusahaan tidak hanya dapat meningkatkan kinerjanya jika perusahaan dapat peduli pada seuam steakholdernya termasuk lingkungan sosialnya. Penelitian ini berkonstribusi pada perusahaan agar dapat meningkatkan etika kepedulian social dan melakaukan pengungkapan terhadap kegiatan sosialnya agar dapat meningkatkan kinerja perusahaan .
\end{abstract}

Kata Kunci : CSR, Profitabilitas, Covid-19 
68 Refika Sari, Yunita Maharani, ANALISIS CSR DAN HUBUNGANNYA DENGAN PROFITABILITAS..........

\section{Dasar Pemikiran}

Corporate Social Responsibility (CSR) merupakan suatu prinsip kemanusian atau kepedulian perusahaan terhadap steakholdernya atau lingkungan sosialnya dimana etika perusahaan dinilai dari cara perusahaan memperlakukan steakholdernya, CSR mulai dikenal pertama kali di negara Amerika Serikat diabad ke 1900 , Di Indonesia istilah Csr mulai dikenal pada tahun 1980 historinya sama seperti saat munculnya istilah ini dikancah dunia dimana Csr telah terjadi sebelum istilah ini dikenal melaui konsep sealt belt atau investasi sosial konsep Csr semakin dikenal dilingkungan bisnis dunia, Profitabilitas adalah pengukuran kinerja keuangan suatu perusahaan bagaimana perusahaan menghasilkan laba menjadi hal yang penting dalam menilai kinerja keuangan perusahaan secara kasat mata biaya yang timbul atas investasi sosial atau penerapan Csr menjadi tambahan dalam komponen biaya yang dapat mengurang profitabilitas perusahaan, namun berdasarkan konsep teori steakholder dimana perusahaan membutuhkan dukungan publik untuk tetap mempertahankan kinerjanya sehingga Csr dianggap akan memberikan dampak yang postif terhadap kinerja perusahaan dalam jangka panjang.

Pertumbuhan ekonomi pada kuartal 12019 melambat dikarenakan tertahannya konsumsi masyarakat akibat adanya pandemi COVID-19, di mana masyarakat menegah ke atas menahan konsumsinya pada awal tahun. Hal ini mengakibatkan ekonomi indonesia kuartal 1 hanya tumbuh 5,07\% dibandingkan dengan periode yang sama pada tahun sebelumnya. Konsumsi rumah tangga menjadi salah satu acuan untuk mengukur ekonomi secara keseluruhan dikarenakan tren pertumbuhan konsumsi selalu sejalan dengan laju ekonomi. Saat konsumsi melambat, hampir dipastikan akan berefek pada agregat pertumbuhan ekonomi. Imbas dari konsumsi masyarakat yang tertahan dirasakan oleh beberapa emiten atau perusahaan publik yang bergerak dibidang sektor konsumer. Secara umum kinerja emiten konsumer masih tumbuh. Namun, ada beberapa kinerja perusahaan besar khususnya yang bergerak di industri makanan dan minuman justru mengalami penurunan laba pada kuartal I 2019 akibat adanya pandemi covid 19 untuk itu penepitian ini akan menganalisis bagaimana hubungan Corporate sosial 
responsibility dengan profitabilitas perusahaan pada perusahaan manufaktur sektor konsumsi diera pandemi covid 19 .

CSR didefinisikan sebagai komitmen bisnis untuk memberikan kontribusi bagi pembangunan ekonomi berkelanjutan, melalui kerja sama dengan para karyawan serta komunitas setempat maupun masyarakat umum untuk meningkatkan kualitas kehidupan dengan cara yang bermanfaat baik bagi bisnis sendiri maupun pembangunan. Pada dasarnya program CSR berkaitan erat dengan konsep sustainability development (pembangunan berkelanjutan). Kegiatan CSR berlandaskan pada triple bottom line, yaitu ekonomi, sosial, dan lingkungan. Sinergi tiga elemen ini merupakan kunci konsep pembangunan berkelanjutan. Pelaksanaan program CSR berkelanjutan akan memberikan dampak positif dan manfaat lebih besar baik kepada perusahaan itu sendiri maupun para stakeholders dan akan menciptakan kehidupan masyarakat yang lebih sejahtera dan mandiri (Murad, 2020).

Pada prinsipnya CSR merupakan komitmen perusahaan terhadap kepentingan para stakeholders dalam arti luas daripada sekedar kepentingan perusahaan balaka. Meskipun secara moral adalah baik bagi perusahaan mengejar keuntungan, bukan berarti perusahaan dibenarkan mencapai keuntungan tersebut dengan mengorbankan kepentingan-kepentingan pihak lain yang terkait. Oleh karena itu setiap perusahaan harus bertanggung jawab atas tindakan dan kegiatan dari usahanya yang mempunyai dampak baik langsung maupun tidak langsung terhadap stakeholders-nya dan lingkungan dimana perusahaan melakukan aktivitas usahanya. Sehingga secara positif, hal ini bermakna bahwa setiap perusahaan dalam menjalankan aktivitasnya sedemikian rupa, pada akhirnya mampu meningkatkan kesejahteraan para stakeholders-nya dengan memerhatikan kualitas lingkungan kearah yang lebih baik (Nugroho, 2020). .

Perusahaan yang telah melaksanakan aktivitas CSR akan mengungkapkannya dalam laporan tahunan perusahaan, yang kemudian disosialisasikan ke pihak berkepentingan secara luas. Pengungkapan CSR akan meningkatkan citra dan kepercayaan pihak berkepentingan terhadap produk dan jasa perusahaan sehingga akan mengalirkan dananya ke perusahaan. CSR dianggap sebagai investasi sosial yang 
$\mathbf{7 0}$ Refika Sari, Yunita Maharani, ANALISIS CSR DAN HUBUNGANNYA DENGAN PROFITABILITAS..........

menghasilkan keuntungan bagi perusahaan. untuk menganalisis tindakan corporate sosial resposibility dan pengungkapanya serta pengaruhnya terhadap profitabilitas perusahaan pada masa pandemi covid 19 dimana banyak perusahaan yang mengalami menurunan profit, tujuan penelitian ini adalah untuk melihat hubungan aktivitas dan pengungkapan Csr terhadap profitabilitas perusahaan pada masa pandemi 2019.

Operasional variabel pada penelitian ini terdiri dari CSRj merupakan indeks dari CSR yang diperoleh dengan cara membagi jumlah item indikator yang diungkapkan perusahaan dalam laporan tahunan dengan jumlah item yang seharusnya diungkapkan perusahaan sesuai dengan pedoman yang digunakan, yaitu menggunakan G4 terdapat 91 item. Jumlah item indikator menggunakan skala 0 sampai 1 sesuai dengan yang diungkapkan perusahaan. Semakin banyak perusahaan mengungkapkan item pengungkapan sosialnya dan semakin bagus kualitas pengungkapnnya, maka akan semakin tinggi nilai perusahaannya, sehingga CSRj dirumuskan sebagai berikut (Nopari dan Lestari , 2016):

$$
\operatorname{CSRI}_{j}=\frac{\Sigma X_{i j}}{n_{j}}
$$

\section{Keterangan :}

CSRIj : Corporate Social Responsibility Index perusahaan $\mathrm{j}$.

nj : Jumlah item untuk perusahaan $\mathrm{j}$.

$\Sigma X i j \quad$ : Menggunakan skala 0 sampai 1 , per item indikator yang diungkapkan.

Profitabilitas merupakan kemampuan perusahaan dalam menghasilkan laba selama periode tertentu, dengan memanfaatkan asset dan modal tertentu melalui penjualan. Dalam penelitian ini, ROA digunakan sebagai rasio untuk mengukur tingkat profitabilitas perusahaan. Return on Asset (ROA) menunjukkan seberapa banyak return atau penghasilan perusahaan dengan memanfaatkan penggunaan aktiva perusahaan. Adapun rumus untuk melakukan perhitungan ROA adalah sebagai berikut :

$$
\mathrm{ROA}=\frac{\text { Laba Bersih }}{\text { Total Aset }}
$$


Adanya perbedaan hasil penelitian yang dilakukan oleh anggara satria putra tahun 2015 yang menyatakan bahwa Csr memilikimpengaruh positif namun tidak signifikan yerhadap profitabilitas sedangkan Sayekti dan Wondabio (2007) mengungkapkan tingkat pengungkapan CSR berpengaruh negatif terhadap Earning Response Coefficient. Maksudnya adalah makin luas tingkat pengungkapan yang dilakukan oleh perusahaan akan makin mengurangi tingkat ketidakpastian yang mengenai prospek perusahaan. Berdasarkan Teori yang ada serta adanya perbedaan literature yang terhadap hubungan kedua variable diatas maka Hipotesis dari penelitian ini adalah

Ha : Corporate Social Responsibility Berpengaruh Positif signifikan terhadap kinerja keuangan di masa Pandemi covid 2019.

\section{Metode Penelitian}

Jenis Penelitian ini adalah penelitian kuantitatif. Metode Penelitian Kuantitatif dapat diartikan sebagai metode penelitian yang berlandaskan pada filsafat positivisme, digunakan untuk meneliti pada populasi atau sampel tertentu, pengumpulan data menggunakan instrumen penelitian, analisis data bersifat kuantitatif/statistik, dengan tujuan untuk menguji hipotesis yang telah digunakan, Penelitian ini menggunakan data sekunder yang diperoleh dari pihak lain dalam bentuk laporan tahunan perusahaan manufaktur yang dipublikasi Bursa Efek Indonesia (BEI) periode 2019, Penentuan populasi dalam penelitian ini perusahaan manufaktur sub sektor makanan dan minuman yang terdaftar di BEI sebanyak 24 perusahaan.pengajuan dilakukan dengan anaisis linier sederhana yang menguji keterkaitan hubungan antara variable $\mathrm{X}$ yaitu pengungkapan corporate social responsibility dengan Profitabilitas .

\section{Hasil dan Pembahasan}

Uji Regresi Sederhana

Persamaan yang didapat dari hasil regresi sederhana yaitu

$$
\mathrm{Y}=0,3978+22,672 \mathrm{X}+\mathrm{e}
$$

Dimana : 
72 | Refika Sari, Yunita Maharani, ANALISIS CSR DAN HUBUNGANNYA DENGAN PROFITABILITAS..........

$\mathrm{Y}=$ Nilai Perusahaan

$\mathrm{a}=$ Konstanta

$\mathrm{X} \quad=$ Corporate Social Responsibility

e $\quad=$ Standar Erorr

Regresi tersebut dapat diinterprestasikan sebagaimana berikut ini :

a) Nilai konstanta sebesar 0,3978 yang artinya jika variabel independen sama dengan nol maka profitabilitas adalah 0,3978

b) Koefisien regresi corporate social responsibility (CSR) 22,672 menunjukkan bahwa setiap kenaikan nilai 1 satuan pada corporate social responsibility akan menaikan profitabilitas sebesar 22,672

Hasil Uji Hipotesis

Uji F

Hasil uji $\mathrm{F}$ dilakukan untuk melihat pengaruh secara simultan atau bersama variabel bebas yaitu Corporate Social Responsibility terhadapProfitabilitas pada perusahaan Barang konsumsi yang terdaftar di Bursa Efek Indonesia. Hasil uji F tersebut dapat dilihat pada tabel 1 berikut

Tabel 1. Hasil Uji F

\begin{tabular}{lllll}
\hline & & $\begin{array}{l}\text { Sum of } \\
\text { Squares }\end{array}$ & F & Sig. \\
\hline 1 & $\begin{array}{l}\text { Regressi } \\
\text { on }\end{array}$ & 1453.285 & 3.482 & $.042^{\mathrm{a}}$ \\
& Residual & & \\
& & 56708.638 & & \\
& & & \\
\hline
\end{tabular}

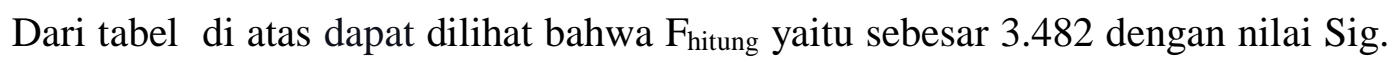
yaitu 0.042. Pengujian hipotesis dalam penelitian ini taraf signifikansi yaitu 5\% 
Berdasarkan hasil tersebut dapat dilihat bahwa Csr berpengaruh postif signifikat terhadap profitabilitas pada perusahaan barang konsumsi yang terdaftar di BEI pada masa covid 2019 atau tahun 2019.

\section{Hasil Uji T}

Hasil uji t dilakukan untuk melihat pengaruh secara parsial atau sendiri variabel bebas yaitu Ukuran perusahaan terhadap nilai perusahaan pada perusahaan yang terdaftar di Bursa Efek Indonesia. Hasil uji t tersebut dapat dilihat pada tabel 3 berikut:

Tabel 2. Hasil Uji 2

\begin{tabular}{cc|c|c}
\multicolumn{4}{c|}{ Coefficients $^{\mathbf{a}}$} \\
\hline \multicolumn{2}{c|}{ Model } & $\mathrm{T}$ & Sig. \\
\hline 1 & $\begin{array}{l}\text { (Constant) } \\
\text { Profitabilitas }\end{array}$ & 1.142 & 0.042 \\
& & & \\
\hline
\end{tabular}

a. Dependent Variable:

Profitabilitas

Dari tabel di atas dapat dilihat bahwa thitung yaitu sebesar 1.142 dengan nilai Sig. yaitu 0.042. Pengujian hipotesis dalam penelitian ini taraf signifikansi yaitu 5\% Berdasarkan hasil tersebut dapat dilihat bahwa Csr berpengaruh postif signifikat terhadap profitabilitas pada perusahaan barang konsumsi yang terdaftar di BEI pada masa covid 2019 atau tahun 2019.

\section{Pembahasan Hasil Penelitian}

Analisis Corporate Sosial Responsibility dan Hubunganya dengan Profitabilitas di Pandemi covid 2019 Pada Perusahaan Barang Konsumsi Di BEI. Berdasarkan Hipotesis dan teori steakholder bahwa kepedulian atau etika perusahaan terhadap steakholder dan lingkunganya akan memberikan dampak positif terhadap kinerja 


\section{4 | Refika Sari, Yunita Maharani, ANALISIS CSR DAN HUBUNGANNYA DENGAN PROFITABILITAS..........}

keuangan perusahaan dikaranekan perusahaan yang melakukan csr dan mengungkapkanya akan menjadi perhatian steakholernya dalam menjaga kegiatan usaha yang menghasilkan profitabiitas perusahaan yang baik pernyataan ini dibuktikan dengan hasil penelitian pada uji regresi sederhana yang menghasilkan nilai positif dan signifikan antara Corporate social responsibility yang dikur dengan pengungkapanya dengan profitabilitas yang diuur dengan return on assetnya bahkan diera krisis ekonomi tahun 2019 dimana rata tara perusahaan mengalami penurunan kinerja namun hasil ini tetap menyatakan bahwa perusahaan yang melakukan pengungkapan Csr lebih banyak mengalami peningkatan kinerja yang baik pula.

Hasil penelitian ini sejalan dengan hasil penelitian yang dilakukan oleh asil ini sesuai dengan penelitian yang dilakukan Rosdwianti, Dzulkirom, dan Zahroh (2015) yang menyatakan bahwa besarnya pengungkapan Corporate Social Responsibility(CSR) berpengaruh positif terhadapprofitabilitas yang diukur menggunakan Return on Equity(ROE), dan Earning per Share(EPS). Hal tersebut menunjukkan bahwa semakin banyak perusahaan melakukanpengungkapan CSR dalam laporan tahunan maka profitabilitas perusahaan akan mengalami peningkatan. Dan Penelitian yang dilakuakn Oleh Roby herlianto dan agung Jurliarto (2012) yang menyatakan bahwa Corporate Social Responsibility(CSR) Berpengaruh positif signifikan terhadap Profitabilitas namun penelitian ini bertentangan dengan Penelitian yang dilakukan oleh anggara satria putra tahun 2015 yang menyatakan bahwa Csr memilikimpengaruh positif namun tidak signifikan yerhadap profitabilitas sedangkan Sayekti dan Wondabio (2007) mengungkapkan tingkat pengungkapan CSR berpengaruh negatif terhadap Earning Response Coefficient. Maksudnya adalah makin luas tingkat pengungkapan yang dilakukan oleh perusahaan akan makin mengurangi tingkat ketidakpastian yang mengenai prospek perusahaan.

\section{Simpulan}

Beradasrkan Hasil penelitian diatas maka dapat disimpulkan bahwa perlu adanya etika social dari perusahaan dan pengungkapanya dalam hal mempertahankan kinerja perusahaan, penelitian ini mengkonstribusikn untuk para pengusaha untuk tetap peduli 
pada lingkungan ebagai nilai promosi terhadap kinerja perusahaan, penelitian ini terbatas hanya pada perusahaan manufaktur barang konsumsi yang terdaftar di BEI Tahun 2019, selanjutnya penliti selanjutnya dapat lebih memperluas permasalahan dan pengujian untuk dapat hasil yang lebih maksimal terkait hal hal yang berhubungan dengan etika lingkungan dan kinreja perusahaan. 
76 Refika Sari, Yunita Maharani, ANALISIS CSR DAN HUBUNGANNYA DENGAN PROFITABILITAS..........

\section{DAFTAR PUSTAKA}

Murad, A. (2020). Pengaruh Corporate Social Responsibility terhadap Nilai Perusahaan dan Volume Perdagangan (Studi Pada Perusahaan Plastik Dan Kemasan Yang Terdaftar di BEI Periode 2013-2017. 8(2), 152-166.

Novari, P. M., \& Lestari, P. V. (2016). Pengaruh Ukuran Perusahaan, Leverage, Dan Profitabilitas Terhadap Nilai Perusahaan Pada Sektor Properti Dan Real Estate. E-Jurnal Manajemen Universitas Udayana, 5(9), 252428.

Nugroho, T. A. (2020). Pengaruh Corporate Social Responsibility Pada Kinerja Keuangan Perusahaan Dan Implikasinya Terhadap Nilai Perusahaan Pertambangan Yang Terdaftar Di Bursa Efek Indonesia Tahun 2015-2019.

Putra, Anggara Satria. 2015. Pengaruh Corporate Social Responsibility Terhadap Profitabilitas Perusahaan Studi Empiris Pada Perusahaan Sektor Industri Barang Konsumsi yang Terdaftar Bursa Efek Indonesi Tahun 2010-2013.

Rosdwianti, M.K., Moch Dzulkirom A.R, dan Zahroh, Z.A. 2016.'Pengaruh Corporate Sosial Responsibility (CSR) terhadap Profitabilitas Perusahaan (Studi Pada Sektor Industri Barang Konsumsi Yang Terdaftar Di Bursa Efek Indonesia Periode 2013-2014)”. Jurnal Administrasi Bisnis (JAB), Vol. 38, No.2, hlm 16-2

Robby Heryanto,Agung Juliarto.2012 Pengaruh Corporate Sosial Responsibility (CSR) terhadap Profitabilitas Perusahaan Jurnal Akuntansi DiponegoroVol. 6

Sayekti, Yosefa dan Ludovicus Sensi Wondabio. 2007. "Pengaruh CSR Disclosure terhadap Earning Response Coefficient (Suatu Studi Empiris pada Perusahaan yang Terdaftar di Bursa Efek Jakarta)." Makalah disampaikan pada Simposium Nasional Akuntansi IX, Makassar, 26-28 Juli 2007. 